\title{
Twenty-First Century Instructional Classroom Practices and Reading Motivation: Probing the Effectiveness of Interventional Reading Programs
}

Taoufik Boulhrir*

Department of English Studies, Discourse, Creativity, and Society, USMBA, Saiss-Fes, Morocco

Corresponding author: Taoufik Boulhrir, E-mail: Taoufik.boulhrir@usmba.ac.ma

\begin{tabular}{l} 
ARTICLE INFO \\
\hline Article history \\
Received: June 18, 2017 \\
Accepted: July 30, 2017 \\
Published: July 31, 2017 \\
Volume: $5 \quad$ Issue: 3 \\
\hline
\end{tabular}

Conflicts of interest: None

Funding: None

\begin{abstract}
Twenty-first century education has undoubtedly witnessed changes of the definition of literacy to cope with the economic, social, and intellectual trends. Technological advances, which include skills of communication, creativity, critical thinking, and collaboration have become key in education, especially when dealing with literacy and reading motivation. As motivation hinges around two major theoretical approaches, intrinsic and extrinsic, numerous studies argue for the first to be more sustainable in enhancing reading motivation. Accordingly, many researchbased interventional programs have emerged since the late nineties with increasing popularity to offer answers to the dwindling rates in reading among youth. This article discusses traits of $21^{\text {st }}$ century education in light of trends and challenges as it probes the effectiveness of some interventional programs that are meant, and argued for, to enhance literacy skills and reading motivation.
\end{abstract}

Key words: Intrinsic, Extrinsic, Reading Motivation, Literacy Skills, Interventional Programs

\section{INTRODUCTION}

Educators as well as educationists have worked on reading motivation for over three decades to find effective ways to motivate students to read and find academic success. Researchers have come up with different definitions of what 'reading motivation' really is. Despite relative differences in defining reading motivation and what it consists of, there is a general consensus about motivation being the will, the desire, the urge, the intention and/or the decision to engage (or not to engage) in a certain reading activity (Cambria and Gurthie, 2010; Schiefele, 1999). Ulrich Schiefele, for instance, simply defines it as the "wish or intention to engage in a certain activity" (p. 259). Jill Janes, in her 2008 study on families, motivation and reading, introduced motivation as a "concept" (p. 8). This concept is one of the main drives behind decisions related to reading. Individuals read different genres of literature and they read for different reasons. These reasons may vary from one person to another. Research has categorized types of motivation into two major categories: intrinsic motivation and extrinsic motivation.

Despite the consensus on the definition and the dichotomous nature of motivation, there is an ongoing debate on the relationship between reading competence/comprehension and reading motivation. This debate extends into a further discussion on whether the relationship is one of cause, effect, or both. It also includes a consideration of the significance (and ties) of comprehension and fluency, both being acquired and required skills for reading. Major studies have been conducted to find evidence of the relation comprehension has with motivation, and to find links between fluency and comprehension in correlation with reading motivation. Theoretically, self-efficacy, self-determination and expectancy value theories agree that developing reading competence in students positively impacts their intrinsic reading motivation. Interventional reading programs are generally keen on working on intrinsic motivation and seek effectiveness in doing so.

This article is set forth to present a review of literature pertaining to $21^{\text {st }}$ century education characteristics and theoretical approaches to reading motivation. Instructional classroom practices constitute the practical aspect of this article in that it exposes the characteristics of two internationally recognized US based reading programs against their effectiveness and flaws. It is an attempt to shed light upon theoretical approaches of reading motivation in light of demands of $21^{\text {st }}$ century education and the effectiveness of two practical interventional programs that enhance intrinsic reading motivation in K-6 classrooms based on research findings. Specifically, characteristics of the CORI and AR programs will be described in terms of their founding and supporting literature, then analyzed and critiqued in light of their flaws highlighted by skeptic researchers. To do so, academic work and research studies that have taken place since the late 90's were reviewed in this article in terms of their foci on foundations and characteristics of $21^{\text {st }}$ century education, reading motivation, and traits and criticism of the AR and CORI approaches in catering for the intrinsic motivation of 
$21^{\text {st }}$ century readers in elementary education. The reviewed literature includes academic works which were primarily selected based on their specific concerns and scopes being directly linked to the following three main categories: theoretical background of $21^{\text {st }}$ century instructional practices relevant to literacy and reading motivation, founding and supporting research of AR and CORI, and criticism directed at the validity of the findings and claims of supporting research, respectively.

\section{TWENTY-FIRST CENTURY EDUCATION AND READING MOTIVATION}

\section{Reading Literacy Skills in the $21^{\text {st }}$ Century Education}

Reading and literacy attitudes are defined by McKenna, Kear and Ellsworth (2009) as acquired "predispositions to respond in a consistently favorable or unfavorable manner"(p. 934) with respect to aspects of reading. Modern education requires individuals to possess a set of skills that are considered essential for modern economy and knowledge acquisition. For this purpose, international assessments like Trends in International Mathematics and Science Study (TIMSS) and Progress in International Reading Literacy Study (PIRLS) are administered across the globe in participating countries to assess the extent to which participants are capable of economic growth. The more students possess critical thinking and problem solving skills, the better they (are believed to) do on such tests. Accordingly, King (2012) concludes, "high scores indicate the capability of achieving an increase in gross domestic product (GDP)" (p. 22). High scores imply that students are not only able to decode "text", regardless of its genre, but they are also able to incorporate their text comprehension to interpreting, solving, and relating to real life implications.

Not only is education meant to prepare individuals to be literate for real life challenges, it is also meant to engage them in learning environments where it "is often social, interactive, and ongoing, as opposed to individualistic, isolated, competitive and static" (Guinier, 1998, p. 263). In order to understand what the learner needs to learn so as to be an effective reader in a modern world, key elements need to be identified and applied in a classroom environment. Some of these elements are critical thinking and goal setting, communication, decision making/choice based on interest, and access/availability of resources, to name a few.

An engaging motivating reading environment is characterized by interactivity and openness to the world. That is, such an environment must promote highly needed skills such as:

1. Communication: which occurs both in class, in person and at home with parents or relatives;

2. Creativity: which enables students to create and reflect on their own understanding of materials being read/ learned;

3. Critical thinking: which happens before, during, and after reading activities such as questioning and predicting;

4. Collaboration: which involves students reading in teams and analyzing what they read (Monroe, 2004. pp. 82-84).
The above-mentioned four Cs. skills (as they are commonly referred to) are believed to be critical to $21^{\text {st }}$ century education, especially when reading and literacy skills are involved. The concept of 'literacy', apparently, involves more than just the text-coding and writing abilities. In this respect, Jones and Flannigan (2015) affirm, "Prior to the year 2000, the ubiquitous term, literate, defined one's ability to read and write. Its meaning delineated the educated from the uneducated, as being illiterate proved an unthinkable dilemma" (p. 3). What Monroe and Jones et al. attempt to point out is the change in understanding of literacy with consideration to world trends in education. Monroe adds that classrooms where internet inquiry and online discussions take place are capable of generating students with literacy skills. Not only that, "such a classroom becomes a laboratory for social justice" (p. 21). It is not fair, in other words, to teach students how to inquire, to communicate, to read and love to read the same way it was done in the $20^{\text {th }}$ century - a century during which the ability to decode a written/printed text, and the ability to write were sufficient to be counted as literacy, whereas the lack of this ability indicated a status of "illiteracy" (Prensky, 2001).

Since the late 90 s and beginning of the $21^{\text {st }}$ century, it has been evident that technology has become one of the most significant phenomena in daily human lives. It has had a tremendous impact on reading motivation in the classroom. Research suggests that the use of technology has been taken for granted in many households, and it has become one of the most effective teaching/learning tools in the classrooms. Teachers often use computer-assisted instruction (CAI) to provide students with access to reading content in a motivational context (Murray and Rabiner, 2014).

Given the fact that the world has witnessed a tremendous shift in technology use in economics and social communications, it is relevant to take into account the use of technological advances in education, which takes place in a "Digital Age" as described by Jerald (2009) and King (2012), among others. A digital age, by necessity, requires reflection upon digital literacy and what it might refer to. According to Monroe (2004), digital literacy includes: (i) basic, scientific, and technological literacies, (ii) visual and information literacies, and (iii) multicultural literacy and global awareness. These elements are essential when it comes to identifying reading skills and motivation. A good education ought to consider developing individuals who are not only able to read (decode text) and write but also able to comprehend and communicate. All this should be done without compromising the pivotal role of reading with the intrinsic will to reflect on the world and its trends. That is, being digitally literate does not mean stepping away from reading for information and leisure purposes.

The world nowadays involves different texts and au courant ways to communicate and convey meaning (Lamb and Larry 2011, pp. 56-63). There is a legitimate reason to consider technology when thinking, planning, and discussing reading motivation. Several studies on the relationship between reading motivation and technology have concluded that students in general show a positive attitude and elevated 
engagement with long lasting stamina when reading is conducted using some form of technology. This is, consequently, related to combining the use of technologies with effective strategies of literacy instruction that can help students develop the skills and confidence they need to be successful readers (Dalton and Hannafin, 1988, pp. 27 - 23). In another study, Lamb et al. (2011) conclude that one third of the students who participated in a study expressed their will to read more books for their personal enjoyment if they were able to use an e-reader or a computer. As recent research suggests, there is compelling evidence that teachers, parents, education authorities start, or continue, to consider technology as an inevitable tool to enable students to gain independence in their learning and adopt lifelong reading practices. Reading practices are generally believed to be driven either by intrinsic or extrinsic motivational factors.

\section{Intrinsic Motivation vs. Extrinsic Motivation}

Intrinsic motivation is generally defined as the self-determination to do something or be engaged in a certain activity. "To be motivated means to be moved to do something" as Ryan et al. (2000) put it before they elaborate, "a person who feels no impetus or inspiration to act is thus characterized as unmotivated, whereas someone who is energized or activated toward an end is considered motivated" (p. 54). Hence, intrinsic reading motivation is the self-determination (hence self-determination theory) of an individual to be engaged in reading for personal reasons and self-satisfaction. According to Guthrie et al. (1996) motivated readers are "motivated" because they want to read; they pick up books on their own and read. They do so for the fun, challenge, enjoyment, entertainment, or the learning entailed, rather than external prods, rewards, pressures, or rewards. These students do not necessary need to be assigned to read for homework to do so, since they are driven by a personal will to read. Their engagement in reading may develop as an outcome of the intrinsic value they attribute to reading. In their study of reading motivation in $4^{\text {th }}$ graders, Durik et al. (2006) found that the extent to which students would continue to read, for the sake of reading, through their adolescence/high school has a great deal to do with the value they place on reading. This intrinsic motivation is also an outcome of several factors that attribute to its development.

One of such factors is curiosity (Wang and Guthrie, 2004), which is argued to be one of the main drives of intrinsic motivation, an innate competence that is specific to human behavior. When driven by curiosity, students tend to read more frequently, and for longer periods of time. They read because they simply want to know something or learn about something; they decide on their own what to read, when to read, and for how long they want/need to read. They read to satisfy their curiosity. Allan Wigfield and John Guthrie (1997) relate curiosity to interest value, another aspect of intrinsic motivation, in that curiosity leads to reading which, in turn, leads to placing value on such activity as a source of satisfaction, especially when readers become completely involved that they lose track of time (Nell, 1988).

Although interest is related to curiosity, it is identified by Schiefele (1999) as an intrinsic motivational factor in the sense that reading occurs intrinsically due to the existence of interest in reading. That is, students read more efficiently when they are interested in reading, especially in certain topics that relate to their lives. In this respect, Padak and Potenza-Radis (2010) argue that for reading to be effective and done intrinsically, "what students read [...] must be connected to [their] interests and lives" (p. 1). Interest includes both personal interest, which refers to emotional attachment to a certain topical text, and situational interest which involves a temporary state instigated by some features in the text, but not necessarily all of it (Schiefele, 1999). An example of personal interest is reading literature on visual arts by a reader whose hobby is painting. An example of situational interest is reading about a topic/event that is currently all over the news. Again, this implies how interest is directly related to curiosity despite its potential influence on intrinsic reading motivation.

Other factors of intrinsic motivation are reading efficacy and involvement (Janes, 2008). While reading efficacy is directly related to reading comprehension as a motivator, involvement "is the enjoyment of experiencing different texts" (p. 10). The notion of being involved in reading is a state of being immersed in the activity of reading for enjoyment or leisure purposes. It is what researchers like Csikszentmihalyi and Nakamura (2002) call "the flow experience", an experience that takes the reader to a virtual world. This experience is also referred to by Nell (1988) as an "intense and highly energized state of concentrated attention" (p. 263). In other words, when readers enjoy being taken to "different worlds" during reading activities and they lose track of time, it becomes a source of satisfaction and entertainment which, in turn, becomes a strong motivating factor of their desires to read.

It is worth being noted, however, that these are only some factors, among others, that work hand in hand with extrinsic motivation, which research has argued to be another kind of motivation that drives individuals toward reading. While the theories behind intrinsic motivation argue that a student is more likely to engage in a reading activity because it is inherently enjoyable or desirable, some researchers have traditionally suggested that besides intrinsic motivation factors, there are also extrinsic reasons that motivate students to read. Extrinsic motivation is argued to vary in terms of its autonomy (Ryan et al., 2000). Thus, "it can either reflect external control or true self- regulation” (p. 54). Ryan et al.'s study of the distinction between types of motivation, in light of classical definitions and contemporary ones, introduce extrinsic motivation as being any expected reward or gain other than "curiosity and interest", for instance. For them, this type of motivation most basically means doing something because of a separable outcome that is expected to be gained upon fulfillment of such activity. In other words, students may engage in reading for a variety of expected tangible and intangible rewards (Chen and $\mathrm{Wu}, 2010$ ), apart from the reading being interesting, enjoyable, and/or entertaining in itself.

Studying extrinsic motivation in terms of the relationship between home reading and literacy skills in school, researchers have concluded that extrinsic motives to read may vary 
from one social setting to another, and yet share some common ground. Families as well as school educators may contribute in one way or another to the provision of such external motives for students to read. A set of these separable rewards are, but not limited to, the following examples: (i) grades, (ii) social practice, (iii) competition, and (iv) compliance and choices (Demos and Foshay, 2010; Durik, Vida, and Eccles, 2006; Sullivan, 2004; Wang and Gurthie, 2004).

i. Grades are an aspect that only teachers and school programs may implement to foster reading motivation in students. Although closely associated with recognition (Ryan and Deci, 2000), grades are believed to be strong in engaging young students in reading and learning to read. "A student could be motivated to learn a new set of [reading] skills because he or she understands their (grades') potential utility or value or because learning the skills will yield a good grade and the privileges a good grade affords" (p. 55).

ii. "Social Practice" is quoted to be the perspective in which reading must be viewed (Knoester, 2009, p. 677). Adolescents, for instance, decide to read or not to read depending on how this act is perceived in society. If reading regarded favorably against other forms of entertainment, per se, then it is more likely that they embrace reading as one of their activities (Baines, 2009). Mucherah and Yoder (2008) explain that one of the reasons why students avoid reading is the fact that it has become less socially acceptable. They further argue that not only peer interaction but also peer influence/ pressure strongly affect whether students choose to engage in reading. Social practice can play a negative role in reading motivation as much as it can play a positive one. Moje, Overby, Tysvaer, and Morris (2008) assert that the social aspect of reading is attached to the acquisition of "social capital by providing information that allows for maintenance of social networks" (p. 131). In other words, adolescents often tend to read about topics they generally interact about in their social networks. A group of boys may engage, for instance, in reading about their favorite sports to maintain their image among their peers as being knowledgeable about all that matters in that specific sport. Also, a group of girls may seem to indulge in reading "gossip" magazines because they feel socially pressured to know, and be able to engage in social daily conversations with peers (Winfree, 2013).

iii. Competition is another drive towards reading by means of "the desire to outperform others in reading" McGeown et al. (2013, p. 314). Provided that a competitive setting (peers competing in a classroom, or siblings in the home) involves reading activities, students or siblings may compete via reading more to receive recognition (see 1 above) or grades in case the setting is a classroom.

iv. Compliance and Choice are also extrinsic motivational factors that may mainly be applied in classrooms to have students read. Compliance is usually connected to grades (see 2 above) and reading assignments prescribed by teachers, school programs, school districts/ministries or other education authorities. Where compliance is a major requirement, choice remains one aspect of motivation educators tend to mistakenly neglect. If students are required to comply, educators need to supplement their teaching practices with reading choices that correspond to student's needs. Research indicates that choice, as an extrinsic motivator, has a tremendous impact on students' motivation to read (Reynolds and Symons, 2001). In their investigation of third graders reading motivation in relation to the effects of choices provided of reading materials, the researchers found, "self-determination, autonomy, and control over the learning situation are important aspects of choice" (p. 21).

\section{Reading Competence and Reading Motivation}

Behaviorists and social learning theorists stress the significance of "reinforces in shaping behavior" (Gambrell and Codling, 1997, p. 19). Within such line of thought, Bandura (1986), one of the most acknowledged social theorists, gave credence to the role of competence (hence self-efficacy theory) in shaping and fostering motivation. Self-efficacy theory can be defined as, "people's judgment of their capabilities to organize and execute courses of action required to attain designated types of performances" (Bandura, 1986, p. 391). Similarly, expectancy-value theory views motivation as a result of one's perception of whether the task can be done successfully (Wigfield and Eccles, 2000). Hence, both theories stress the individuals' perception in terms of capability of performance which can be referred to as competence. In support of self-efficacy theory and expectancy-value theory, researchers have repeatedly admitted there is a strong relationship between reading competence/comprehension and reading motivation. This connection lies in the fact that readers become more motivated when they are able to make sense of what they read. They can related to it, question its content, wonder about it, and interact with it and with others about it. In this respect Gambrell and Marinak (2009) argue that what motivates engaged readers to read is not the practice of reading or the act of reading itself, but the gain they achieve from that interaction. It is the outcome of the experience that such readers gain during and after reading. Other researchers agree and link this gain to interest in the sense that it enhances comprehension, which, in turn, enhances reading motivation. In other words, when students choose and read topics they are interested in, their comprehension tends to be higher and their motivation tends to increase accordingly (Guthrie et al., 2006). The relevance of a text to students' interests determines the degree to which they will comprehend as well as the level of engagement they will experience. The more they practice reading of texts with content they are intrinsically motivated to read about, the more they comprehend and connect with those texts.

Moreover, students who are more capable of reading are reported to have more motivation to read compared to struggling readers. Students who are capable of reading fluently, and who enjoy reading, demonstrate strong comprehension skills either regarding leisure reading or assigned reading. On the other hand, poor readers who repeatedly experience 
failure, or struggle to understand during reading activities seem to avoid reading and tend to engage in other activities that involve less reading (Davidson, 2008). Thanks to their enjoyment and comprehension of text materials, the established readers' motivation grows, as well their reading skills. The strugglers' motivation, however, decreases over time and consequently deprives them of the enjoyment of reading, the experience of reading, and the reading skills acquired in that process (Morgan and Fuchs, 2007).

Between students who are successful and motivated readers and others who struggle and "do not like to read", there is a 'grey' area for students who are capable of reading and yet choose not to. Tilley (2009) points out the fact that the number of students who demonstrate an 'aliterate' attitude does not dwindle over time; to the contrary, it increases. Tilly further explains that these kinds of students, despite their ability to read fluently, choose not to read, which entails that reading is by no means made a lifelong habit by these students. A habit that is believed to be a key element in developing a large number of literacy skills such as comprehension, spelling, vocabulary, and grammar (Sanacore and Palumbo, 2010). In their work on middle school students' literacy skills across the curriculum, Sanacore and Palumbo advocate for more opportunities for reading in an attempt to reach out to teachers of all content areas to do their part in engaging students in more reading practices for the sake of comprehension development and reading motivation. Provision of more opportunities to read in the classroom and as homework is capable of reversing 'aliterate' attitudes to positive ones toward reading.

In a ten-year study on elementary and high school students' reading amounts and comprehension, Cunningham and Stanovich (1997) found that there is a solid linkage between exposure to print and reading comprehension, which is said to be developed through reading consistency. In their longitudinal study, they concluded that reading comprehension - along with general knowledge and vocabulary - positively correlated with the amount of reading and frequency; the more students read, and the more frequently they do so, the better their comprehension of unfamiliar texts is. Similar works like Wang and Guthrie (2004), with focus on $4^{\text {th }}$ graders, support these results by claiming that the amount of reading students were exposed to during the investigation reflected correlatively on passage comprehension.

Claiming that there is a connection between reading motivation and reading comprehension is not only supported by several research studies, but it is also backed by the Program for International Students Assessment (PISA) which reports that participating students, from participating countries, who are motivated to read tend to engage in reading on a daily basis (Risinger, 2013). Based on PISA results of 2009 (as cited in Borgonovi, 2011), students who read for pleasure outperform students who were merely participating in reading practices. Accordingly, the comprehension scores of the former were relatively higher than those of the latter. Francesca Borgonovi goes on and accredits reading proficiency - in addition to reading for pleasure, rather than reading practice - to reading motivation and comprehension. She says:
Reading for enjoyment is associated with reading proficiency: PISA finds that a crucial difference between students who perform well in the PISA reading assessment and those who perform poorly lies in whether they read daily for enjoyment, rather than in how much time they spend reading. (p. 2)

Logan and Johnson (2010) and Ülper (2011) support the stronger role of reading for enjoyment over reading practice and further assert that frequency and amount of reading is not necessarily a contributing factor to improving reading comprehension skills. Therefore, researchers advise teachers not to expect significant improvement in reading literacy skills and motivation just by assigning more reading texts or provide more opportunities to read in the classroom and/or outside. They suggest that teachers ought to focus more on sustained reading approaches to reading, like considering students' interests, sparking off their intrinsic motivation, and scaffolding comprehension before, during, and after reading activities.

In the process of investigating the relationship between reading comprehension, fluency, and reading motivation, researchers have identified major elements of reading fluency upon which reading comprehension can be examined in light of its effect on reading motivation (Klauda and Guthrie, 2008). Some researchers have long considered speed and accuracy as key elements of reading fluency (Fuchs, Fuchs, Hosp and Jenkins, 2001). Others have added other components such as pitch, emphasis, duration, pause and phrasing to refer to appropriate expression as key in reading fluency. Distinctively, Wolf and Tami (2001) recognize fluency in terms of not only its constituent parts, but also in terms of the text units. In their study, they stated that researchers, "attempt to define fluency in terms of either its component parts or its various levels of reading sub skills - that is, letter, letter pattern, word, sentence, and passage" (p. 218).

Several studies on the relationship of reading fluency and comprehension in students in elementary to high school have concluded that the more fluent readers are, the better their comprehension of text is (Pinnell et al., 1995; Yovanoff et al., 2005). Studies with a focus on the increase of fluency in relation to comprehension have revealed a correlation in terms of significant gains in both fluency and comprehension. This correlative association is recognized as relevant to motivated/avid readers, new readers, struggling readers, as well as 'aliterate' readers (Chard, Vaughn and Tyler, 2002; Stahl and Kuhn, 2002). These findings, however, have been challenged by claims that indicate a dissociation relationship between fluency and comprehension, especially when accuracy and speed in reading individual words define reading fluency skills. In a study that targeted third-graders, Walczyk, Marsiglia, John, and Bryan (2004) found that reading aloud a list of words in class revealed no correlation between literal comprehension and accuracy in reading.

In this respect, many teachers of all content areas report they encounter students who struggle with reading comprehension, which is argued to be directly related to reading motivation and reading practice. Students also complain, "they do not like to read or that they are not good at read- 
ing" (Risinger, 2013, p. 7). Students' complaints imply that their dislike of reading is a result of the lack of enjoyment in reading or the lack of literacy skills required for engaged reading. This also implies that these students do not often read for leisure, or as a habit, because if they did, they could have acquired a set of literacy skills, e.g. comprehension and fluency that would enable them to read and enjoy reading. Interventions for the sake of enhancing reading motivation have always been initiated at the level of classrooms settings two of which are discussed in this article.

\section{THE EFFECTIVENESS OF ACCELERATED READER AND CONCEPT ORIENTED READING INSTRUCTION}

Interventions to promote and enhance reading motivation can be approached from different perspective including exploiting aspects of technological advances and intrinsic drives that are believed to be behind $21^{\text {st }}$ century readers. Several programs have been introduced to classrooms in order to encourage students to read and develop intrinsic reading habits for the long run. The Accelerated Reader and Concept Oriented Reading Instruction are examples of such approaches which are discussed in terms of analysis of their effectiveness claims.

\section{Accelerated Reader (AR)}

One of the most popular computerized reading programs is Accelerated Reader, a product of Renaissance Learning Company. It is an incentive program that claims and promotes itself as "the answer" to reading motivation and achievement problems (Davidson, 2008). By 2005, the American born product garnered worldwide clientele with offices in Canada, the United Kingdom, and Australia. On their Parents' Guide, Renaissance Learning (2015) introduces the program as:

...a computer program that helps teachers and librarians manage and monitor children's independent reading practice. Your child picks a book at his own level and reads it at his own pace. When finished, your child takes a short quiz on the computer. (Passing the quiz is an indication that your child understood what was read). AR gives children, teachers, and librarians feedback based on the quiz results, which the teacher then uses to help your child set goals and direct ongoing reading practice. Children using AR choose their own books to read, rather than having one assigned to them. This makes reading a much more enjoyable experience as they can choose books that are interesting to them. (p. 2)

It is a program that allows students to choose their own books and finish them by taking quizzes that determine the extent to which they comprehend the text. The company also claims that their products develop life-long readers (Chenoweth, 2001).

Supporters and promoters of AR highlight the fact that the program is fitted with features that determine the reading level of the child prior to starting the program. The pre-tests (STAR) assure readers begin using the program at their levels, which emphasizes intrinsic motivation associated with competence and self-efficacy approach to reading motivation. When they start reading and taking tests, they accumulate points to be redeemed later into rewards, which supports extrinsic motivation in students. Each reading level (associated with length too) has a certain number of points assigned to it. As soon as they complete the quiz, readers receive feedback in a form of a printout from the AR's TOPS (Three Opportunities to Praise Students), which works as an extrinsic incentive to complete each book they start. Here comes the implementation of extrinsic motivation to lure students in reading to gain points. The program is also fitted with an alert system where struggling students, identified by the quizzes, are reported to their teachers for proper intervention (Renaissance Learning, 2015, p. 8).

While they can be useful tools to motivate students to read as well as to ameliorate their reading and comprehension skills, computer assisted programs, such as Accelerated Reader, they have many disadvantages (Topping et al., 1999). In their analytical study of the reading program, Topping and colleagues (2003) underscore advantages and disadvantages of the program. Some of the key advantages of the program highlight the power of the program in developing independent learning and assessment, empowering teachers' prompt and effective intervention, promoting literal comprehension, and increasing motivation to read and achievement, which is measured by offering of certification upon completion of implementation standards. On the other hand, the program falls short, according to the same authors, in catering for students with special education needs and gifted/avid readers who remain dependent throughout the process of reading and unchallenged, respectively. The focus on literal comprehension (instead of a combination of literal and open-ended questions) was listed among the disadvantages despite the fact that it was previously described as an advantage. In addition to technical challenges and the requirement of costly training of teachers for effective implementation of the program, the study underscores the fact that, in some cases, competition to gain AR points becomes so intense that some students read many easy books to outscore their classmates (Topping et al., 2003).

\section{Concept Oriented Reading Instruction (CORI)}

Based on studies done on teaching strategies and reading motivation, Concept Oriented Reading Instruction comes as a curriculum based approach that amalgamates reading instruction in the classroom and conceptual scientific knowledge with support of student motivation to read, not only fiction books but also information based literature. According to Guthrie (2015), it is based on the belief that reading skills can be developed through a variety of strategies and concepts taught together. More specifically, it is a teaching method that defines reading engagement as, "the interplay of motivation, conceptual knowledge, strategies, and social interaction during literacy activities. [...] engagement in reading is crucial for the development of life-long literacy learners". It is also described by its founders as a program 
that "is designed to foster reading engagement and comprehension through the teaching of reading strategies, teaching of scientific concepts and inquiry skills, and its explicit support of the development of student intrinsic motivation to read". This definition places comprehension and engagement as essential properties for fostering reading as a lifelong skill and practice. These longitudinal skills can be fostered by implementing effective strategies in the classroom (National Reading Panel, 2000).

It is worth to note that CORI adopts the recommendations of the American National Reading Panel Report (ANRPR) that came out in 2000 to affirm that there are seven instructional strategies that "appear to have a firm scientific basis for concluding that they improve comprehension in normal readers" (pp. 4-42). The report listed the so-concluded-as effective strategies in an alphabetical order, rather than significance or degree of effectiveness. The strategies are: (i) comprehension student self-monitoring, (ii) cooperative learning, (iii) graphic organizers, (iv) answering and generating questions, (v) summarizing, and (vi) using a combination of strategies to achieve effective comprehension and longstanding motivation, and is referred to as "multiple strategy" method. (National Reading Panel, 2000, pp. 4-44).

In Addition to the above listed strategies, the CORI program teachers, along with their students, base their work on four phases: observe and personalize to create interest, search and retrieve to learn about the topic, comprehend and integrate learning autonomously and/or strategically, and communicate to others which is basically sharing what one has learned from the experience. The use of such phases indicate that the program is founded on a competence theory basis in that it fosters the ability to set goals, create interest, search, comprehend, and communicate autonomously. Students in such a program entertain some control over their learning as their self-efficacy and self-determination helps them engage and eventually be motivated to continue learning through reading.

Several research studies done on the effectiveness of the CORI program suggest that it is an effective instructional method that instills intrinsic reading motivation in students in grades 3-9 (Guthrie and Davis, 2003). They, among others, confirm the positive impact on students' motivation to read and learn. That said, like any other instructional program, this have been subject to criticism.

\section{PROBING THE EFFECTIVENESS OF ACCELERATED READER AND CONCEPT ORIENTED READING INSTRUCTIONS}

Probing Topping's description of Accelerated Reader's pros and cons points out features of the program that are somehow contradictory or rather vague. For instance, if students become motivated to read, why is it important to validate reading through quizzes and certificates? To add, literal comprehension is highlighted as an advantage, but also as a disadvantage because it does not develop readers' critical thinking via open ended questions, which is a key $21^{\text {st }}$ century skill. Completions to accumulate points seems to defeat the purpose of reading and motivation. Here, reading becomes a way/means to gain rewards or recognition, not to attain its enjoyment as its founders claim. That is, enjoyment here is related to the gains rather than to reading itself.

Reviewing many research studies that speak in favor of the effectiveness of the program are, strangely, either authored by or co-authored by Keith Topping who is a member of the Review Board. (Topping and Paul, 1999; Topping, 2006; Topping and Sanders, 2000; Topping, Samuel, and Paul, 2007). Findings of these studies, according to WWC Intervention Report (2016), were deemed as biased and "ineligible for review because [they do] not use an eligible design" (p. 10). Biggers (2001) goes further to question the validity of many of the supporting research findings based on the claim that they were done by the company's own researchers. More specifically, she identifies five of the 19 research studies were authored by Topping.

Research on the effectiveness of the Accelerated Reader is still characterized by bias, ambivalence, and ineligibility of their designs (WWC Intervention Report, 2016), either in favor or against the program. In "The (Lack of) Experimental Evidence Supporting the Use of Accelerated Reader", Krashen (2003) concludes that:

The results presented here strongly suggest that of the four aspects of AR, access to books, time devoted to reading, tests, and rewards, only the first two are supported by research. There is considerable evidence that providing access to books results in more reading and better reading and considerable evidence that providing time to read results in better reading. There is suggestive evidence that incentives do not promote additional reading in the long term. The AR research literature does nothing to change these conclusions.

(p. 26)

In other words, the factors behind the success of this program are yet to be investigated in further research. Stephen Krashen advocates for a balanced program that allows students to choose books based on their interests rather than some other extrinsic reward. Also, providing time and access to a variety of reading genres and text types for students to choose from may have a bigger impact on motivation, than the one extrinsic incentives may have.

Moving on to the Concept Oriented Reading Instruction, it is worth to remember that the CORI program promotes itself as an instructional program that is designed to improve and to instill long-lasting intrinsic motivation to read in young readers, the question to be asked is: does it work? Despite the favorable conclusions many studies reported about the program, What Works Clearinghouse (WWC), an initiative of the Institute of Education Sciences (IES) at the U.S. Department of Education, published a report in August 2010 on the effectiveness of the CORI program. It is worth mentioning that the WWC was established in 2002 to, "promote informed education decision making by providing educators, policymakers, researchers, and the public with a central and trusted source of scientific evidence about "what works' in education" (IES, 2015). The report identified and investigated 48 studies of the CORI program that were published between 1989 and 2009, all of which were conclusive- 
ly in favor of the effectiveness of the program. The report concludes that WWC is, "unable to draw any conclusions based on research about the effectiveness and infectiveness" (WWC, 2010, p. 1) of the CORI program. The reason is that all the 48 studies cited in the report did not meet the WWC's "evidence standards". For instance, some studies do not use "a comparison group design or a single-case design" (WWC, 2010, p. 5). Moreover, a close look through the bibliography of the report, by the researcher of this present study, reveals that 29 of the 48 research studies were either authored or co-authored by John Guthrie, the founder of the CORI program. Although, it may be legitimate to claim that the founder of the program has simply promoted his own creation though research he authored or co-authored; hence, further research is still needed to investigate the effectiveness of such approach.

\section{CONCLUSION}

In light of the demands century 21 has imposed on researchers, educators, and policy makers to cope with the fast- changing economics in a digital age, it has undoubtedly been necessary to consider the implementation of teaching strategies that effectively develop and maintain literacy skills. There is a general consensus about the necessity of redefining literacy skills in ways that respond to the economic needs and requirements in terms of digital literacy and implementation of the century 21 skills in the classrooms (Jerald, 2009; McKenna et al., 2009; King, 2012; and Jones et al., 2015).

To confront the prominent challenge of the dwindling rates of reading which adversely affect literacy skills around the world, many interventional reading motivation initiatives have been advocated for by researchers claiming potential of enhancing intrinsic reading motivation in the classroom (Renaissance Learning, 2015; Topping et al. 2000; and Guthrie 2015). Such research based programs assert promotion of reading skills and motivation through implementation of teaching methods and strategies that incorporate computer-assisted reading programs (i.e. AR), and the use an amalgam of structural cognitive, social, and reading strategies and motivation (i.e. CORI).

Although perusal of literature respective to such programs indicate prevalent supporting evidence for their effectiveness, further scrutiny of study designs, research ethics, and validity of the findings reveals significant flaws that question the reliability of such programs in achieving in their intended objectives. This article argues that research claims in favor of the effectiveness of any interventional program need to be examined against the validity, and the reliability of their findings considering study methodologies and interests founding such claims. Hence, students' perspectives and input need to be considered in approaching educational problems. In addition, research based educational programs need to be counter-examined by independent organizations and researches to ensure independence, objectivity and sustainability of interventional programs in an education provided as a service rather than a business.

For the sake of discussion, criticism can be directed towards the validity of the claims of both programs in the sense that both seem to heavily rely on research that is characterized by potential bias with conclusions that are likely to be tailored to promote the programs rather than serving the interests of young readers. The case of Accelerated Reader reveals that despite extensive published research that support well-grounded motivation theories, questions can still be raised on the effectiveness of such program. The 'corporate funded' body of research backing the AR's claims can only serve the purpose of promoting the program for profit rather than knowledge in the academic community. This also applies to the CORI program in the sense that the majority of research done on its effectiveness is done by its founders. Numerous of such studies seem to lack many validity and reliability characteristics which scientific research requires for objectivity and unbiased judgments.

\section{REFERENCES}

Baines, L. (2009). Reading \& Happiness. The Phi Delta Kappan, 90(9), 686-688.

Biggers, D. (2001). The argument against Accelerated Reader. Journal of Adolescent \& Adult 45 (1), 72-75.

Borgonovi, F. (2011, September). Do Students Today Read for Pleasure? Retrieved May 8, 2014, from www.oecd.org.

Cambria, J., \& Guthrie, J. T. (2010). Motivating and Engaging Students in Reading. The NERA Journal, Volume 46 (1).

Chard, D. J., Vaughn, S., \& Tyler, B.-J. (2002). A Synthesis of Research on Effective Interventions for Building Reading Fluency with Elementary Students with Learning Disabilities. Journal of Learning Disabilities 35 (5), 386-406.

Chen, P.-H. a.-R. (2010). Rewards for Reading: Their Effects on Reading Motivation. Journal of Instructional Pedagogies 3(1), 1-8.

Chenoweth, K. (2001). Keeping Score. School Library Journal 47(9), 48-51.

Csikszentmihalyi, M., \& Nakamura, J. (2002). The Concept of Flow. Retrieved July 17, 2014, from http://eweaver. myweb.usf.edu.

Cunningham, E. A., \& Stanovich, E. K. (1997, November). Early reading acquisition and its relation to reading experience and ability 10 years later. Developmental Psychology, 33(6), 934-945. doi:http://dx.doi. org/10.1037/0012-1649.33.6.934

Dalton, D. W., \& Hannafin, M. J. (1988). The effects of computer-assisted and traditional mastery methods on computation accuracy and attitudes. Journal of Educational, 28(1), 27-33. Retrieved from www.Cited.org.

Davidson, G. A. (2008). Reading motivation and progress through Accelerated Reader: An action research project (Master>s thesis). The College of St. Scholastica. ProQuest.

Davidson, G. A. (2008). Reading Motivation and Progress through Accelerated Reader: An Action Research Project. The College of St. Scholastica. Ann Arbor: ProQuest.

Demos, E. S., \& Foshay, J. D. (2010). Engaging the Disengaged. Retrieved July 25, 2014, from www.Proquest.org. 
Durik, A. M., Mina, V., \& Eccles, J. S. (2006, May). Task Values and Ability Beliefs as Predictors of High School Literacy Choices: A developmental Analysis. Retrieved June 5, 2014, from http://psycnet.apa.org/.

Fuchs, L. S., Fuchs, D., \& Hosp, M. K. (2001). Oral Reading Fluency as an Indicator of Reading Competence: A Theoretical, Empirical, and Historical Analysis. Scientific Studies of Reading, 5(3), 239-56.

Gambrell, L., \& Marinak, B. (2009). Simple Practices to Nurture the Motivation to Read. Retrieved September 22, 2015, from http:/www.readingrockets.org.

Guinier, L. (1998). Lift Every Voice: Turning a Civil Rights Setback into a New Vision of Social Justice. New York: Simon \& Schuster.

Guthrie, J. (2015). Concept-Oriented Reading Instruction. Retrieved June 6, 2014, from http://www.cori.umd.edu/

Guthrie, J. T., \& Davis, M. H. (2003). Motivating Struggling Readers in Middle School through an Engagement Model of Classroom Practice. Reading \& Writing Quarterly 19, 59-85.

Guthrie, J. T., Van Meter, P., McCann, A. D., Wigfield, A., Bennett, L., Poundstone, C. C...., Mitchell, A. M. (1996, July). Growth of Literacy Engagement: Changes in Motivations and Strategies during Concept-Oriented Reading Instruction. Retrieved June 16, 2014, from www. Jstor.org.

Guthrie, J. T., Wigfield, A., Humenick, N. M., Kathleen, P. C. Taboada, A., \& Barbosa, P. (2006, March). Influences of Stimulating Tasks on Reading Motivation and Comprehension. Retrieved May 15, 2014, from http://www.cori. umd.edu/.

Institute of Education Sciences. (n.d.). About the WWC. Retrieved July 17, 2015.

Janes, J. L. (2008). Families, Motivation, and Reading: Pre-Adolescent Students and their Reading Motivation and Family Reading Habits. doi:Order No. 1454596.

Jerald, C. D. (2009, July). Defining a $21^{\text {st }}$ Century Education. Retrieved December 12, 2013, from www.centerforpubliceducation.org.

Jones, B., \& Flannigan, S. (2008). Connecting the Digital Dots: Literacy of the $21^{\text {st }}$ Century. Teacher Librarian, 35(3), 13-16.

King, M. M. (2012, May). Twenty First Cnetury Teadhing and Learning: Are Teachers Prepared? doi:3499020

Klauda, S. L., \& Guthrie, J. T. (2008, May). Relationships of Three Components of Reading Fluency to Reading Comprehension. Journal of Educational Psychology, 100(2), 310-321.

Knoester, M. (2009, May). Inquiry Into Urban Adolescent Independent Reading Habits: Can Gee's Theory of Discourses Provide Insight? Retrieved July 16, 2014, from www.jstor.org/.

Krashen, S. (2003). The (Lack of) Experimental Evidence Supporting the Use of Accelerated. Journal of Children's Literature, 29(2), 16-30.

Lamb, A., \& Larry, J. (2011, October). Nurturing a New Breed of Reader: Five Real World Issues. Retrieved October 4, 2014, from www.scholarworks.iupui.edu.
Logan, S., \& Johnston, R. (2010, May). Investigating Gender Differences in Reading. Educational Review, 62(2), 175-187.

March, J. (2001). How to Design Effective Blended Learning. Retrieved May 24, 2014, from www.academia.edu.

McGeown, S. P., Norgate, R., \& Warhurst, A. (2012). Exploring Intrinsic and Extrinsic Reading Motivation among very Good and very Poor Readers. Educational Research, 54(3), 309-322.

McKenna, M. C., Kear, D. J., \& Ellsworth, r. A. (1995, October). Children's Attitudes toward Reading: A National Survey. Retrieved October 13, 2013, from http://www. jstor.org.

Moje, E. B., Overby, M., Tysvaer, N., \& Morris, K. (2008, Spring). The Complex World of Adolescent Literacy: Myths, Motivations, and Mysteries. Retrieved Agust 1, 2014, from http://www-personal.umich.edu/.

Monroe, B. J. (2004). Crossing the Digital Age: Race, Writing, and Technology in the Classroom. New York: Teachers College Press.

Moore, D. W., Prebble, S., Robertson, J., Waetford, R., \& Anderson, A. (2001). Self-recording With Goal Setting: A self-management programme for the classroom. Educational Psychology, 21(3), 255-265.

Morgan, P., \& Fuchs, D. (2007). Is There a Bidirectional Relationship between Children's Reading Skills and Reading Motivation?. Exceptional Children, 73(2), 165-183.

Mucherah, W., \& Yonder, A. (2008, June 5). Motivation for Reading and Middle School Students' Performance on Standardized Testing in Reading. Retrieved May 14, 20, from http://www.tandfonline.com/.

Murray, D. W., \& Rabiner, D. L. (2014, January 24). Teacher Use of Computer-Assisted Instruction for Young Inattentive. Retrieved May 13, 2014, from http://files.eric. ed.gov/.

Nell, V. (1988). Lost in a Book: The Psychology of Reading for Pleasure. New Haven, CT: Yale University Press.

Padak, N., \& Potenza-Radis, C. (2010). Motivating struggling readers: Three keys to success. New England Reading Association Journal, 45(2), 1-7.

Prensky, M. (2001, October). Digital Natives, Digital Immigrants. Retrieved May 13, 2014, from https://goo.gl/ ZBknrX.

Pinnell, G. S., Campbell, J., Pikulski, J., Kapinus, B., Wixson, K., Gough, P., \& Beatty, A. (1995). Listening to Children Read Aloud. The National Center for Education Statistics. Retrieved July 29, 2014, from http://nces. ed.gov/pubs95/95728.pdf.

Renaissance Learning. (2015). A Parent's Guide to Accelerated Reader. Retrieved June 16, 2014, from http:/www. covenantknights.org/.

Reynolds, L. P., \& Symons, S. (2001, March). Motivational Variables and Children's Text Search. Retrieved July 21, 2014, from http://psycnet.apa.org.

Risinger, A. (2013). Teacher Reading Motivation Practices. Retrieved May 16, 2014, from http:/gradworks.umi.com/.

Ryan, R., \& Deci, E. L. (2000). Intrinsic and Extrinsic Motivations: Classic Definitions and New Directions. Retrieved Jaunary 24, 2014, from www.ideallibrary.com. 
Sanacore, J., \& Palumbo, A. (2010). Middle school students need more opportunities to read across the curriculum. $A$ Journal of Educational Strategies, Issues and Ideas, 83, 180-185. doi:10.1080/00098650903583735

Schiefele, U. (1999). Interest and Learning From Text. Scientific Studies of Reading, 3(3), 257-279.

Stahl, S.A., S. Kuhn, M.R. (2002). Making it sound like language: Developing fluency. The Reading Teacher, 55, 582-584.

Sullivan, M. (2004). Why Johnny Will Not Read. School Library Journal, 50(8), 36-39.

The National Reading Panel. (2000). Teaching Children to Read: An Avidence-based Assessment. Eunice Kennedy Shriver National Institute of Child Health and Human Development.

Tilley, C. (2009). Reading motivation and engagement. School Library Monthly, 26(4), 39-42.

Topping, K. J., \& Paul, T. D. (1999). Computer-Assissted Assessment of Practice at Reading: A Large Scale Survey Using Accelerated Reader Data. Retrieved July 15, 2014, from http://ncset.uoregon.edu/.

Topping, K. J., \& Fisher, A. M. (2003). Computerised Formative Assessment of Reading Comprehension: field trials in the UK. Journal of Research in Reading, 26(3), 267-279.

Topping, K. J. (2006). Accelerated Reader in specialist schools. Scotland: Centre for Peer Learning, University of Dundee.

Topping, K. J., Samuels, J., \& Paul, T. (2007). Computerized assessment of independent reading: Effects of implementation quality on achievement gain. School Effectiveness and School Improvement, 18(2), 191-208.

Topping, K. J., \& Sanders, W. L. (2000). Teacher effectiveness and computer assessment of reading: Relating value added and learning information system data. School Effectiveness and School Improvement, 11(3), 305-337.

Ülper, H. (2011). The Motivational Factors for Reading in Terms of Students. Educational Sciences: Theory And
Practice, 11(2), 954-960. Retrieved from https://eric. ed.gov/?id=EJ927385

Walczyk, J., Marsiglia, C., Johns, A., \& Bryan, K. (2004). Children's Compensations for Poorly Automated Reading Skills. Discourse Processes, 37(1), 47-66. http://dx. doi.org/DOI: 10.1207/s15326950dp3701_3

Wang, J. H.-Y., \& Guthrie, J. (2004). Modeling the Effects of Intrinsic Motivation, Amount of Reading, and Past Reading Achievement on text Comprehension between U.S. and Chinese Students. Retrieved July 2, 2014, from http://onlinelibrary.wiley.com/.

What Works Clearinghouse. (2010). Concept-Oriented Reading Instruction (CORI). US Department of Education: Institute of Education Sciences.

What Works Clearinghouse. (2016). WWC Intervention Report: Accelerated Reader. US Department of Education: Institute of Education Sciences.

Wigfield, A., \& Guthrie, J. T. (1997). Relations Of Children's Motivation For Reading To The Amount And Breadth Or Their Reading. Retrieved July 1, 2014, from http:// www.cori.umd.edu/.

Wigfield, A., \& Eccles, J. (2000). Expectancy-Value Theory of Achievement Motivation. Contemporary Educational Psychology, 25(1), 68-81. http://dx.doi.org/10.1006/ ceps. 1999.1015

Winfree, L. (2013, December). Reading Motivation and Engagement at a Rural Georgia High School. doi:Order No. 3599489

Wolf, M., \& Tami, K.-C. (2001). Reading Fluency And Its Intervention. Scientific Studies of Reading 5(3), 211-239

Yovanoff, P., Duesbery, L., Alonzo, J., \& Tindal, G. (2005, September). Grade-Level Invariance of a Theoretical Causal Structure Predicting Reading Comprehension With Vocabulary and Oral Reading Fluency. Educational Measurement: Issues and Practice, 24: 4-12. doi:10.1111/j.1745-3992.2005.00014.x 